\title{
Nucleation Behaviors of Nd and Dy in TFSA-Based Ionic Liquids
}

\author{
Masahiko Matsumiya \\ Additional information is available at the end of the chapter \\ http://dx.doi.org/10.5772/61292
}

\begin{abstract}
The nucleation behavior of $\left[\mathrm{Nd}^{(\mathrm{III})}(\mathrm{TFSA})_{5}\right]^{2-}$ and $\left[\mathrm{Dy}{ }^{(\mathrm{IIII})}(\mathrm{TFSA})_{5}\right]^{2-}$ in the TFSA-based ionic liquid (IL), triethyl-pentyl-phosphonium bis(trifluoromethyl-sulfonyl)amide, $\left[\mathrm{P}_{2225}\right]$ [TFSA $]$, was investigated in this study. The initial process of $\mathrm{Nd}$ and Dy electrodeposition was evaluated by chronoamperometry, indicating that the initial nucleation and the growth of $\mathrm{Nd}$ and Dy on the electrode surface occurred via instantaneous nucleation at -3.40 and $-3.60 \mathrm{~V}$, respectively. As the overpotential induced more negative, the nucleation mechanism altered from instantaneous to progressive. The number density of $\mathrm{Nd}$ and Dy nuclei tended to decrease as the overpotential gradually increased in this system. Moreover, the potentiostatic electrodeposition of $\mathrm{Nd}$ and Dy metals was examined at $393 \mathrm{~K}$. The surface morphology of the electrodeposits was consistent with the chronoamperometric results. From the EDX and the XPS analyses, we ascertained that the main electrodeposits were rare earth metals with a small quantity of light elements. The series of results enabled us to conclude that the greater part of the electrodeposited Nd and Dy metals was obtained from TFSA-based IL bath by potentiostatic electrodeposition with elevating temperatures, and the control of the water content of the electrolyte was an important factor for the recovery of metallic $\mathrm{Nd}$ and Dy with high purity.
\end{abstract}

Keywords: Electrodeposition, ionic liquids, nucleation, rare earths

\section{Introduction}

Rare earth (RE) elements have been practically applied in various high-tech industries as magnetic and electronic materials [1-3] owing to their unique characteristics deriving from the $4 \mathrm{f}$ electron structure. Neodymium metal in particular is an especially important element as it is the main raw material for permanent $\mathrm{Nd}-\mathrm{Fe}-\mathrm{B}$ magnets used in hard disk drives, mobile 
phones, and automotive motors [4-7]. A large number of Nd-Fe-B magnets have been produced in the world in recent years, and a significant number of spent Nd-Fe-B magnets will accumulate in the near future. It is therefore necessary to recover the RE metals from these secondary waste magnets. Electrowinning methods with high-temperature molten salts have been employed as a conventional recovery process for RE metals because the reduction potential of RE metals is extremely negative. The high-temperature systems needed for these methods for the last several decades. Although the pyrometallurgical process [8-10] of RE metals has actually developed so far, it is difficult to establish a practical recovery system. This kind of pyrometallurgical process using high-temperature media consumed extraordinary amounts of thermal energy, so that it would not be appropriate as an environmental-friendly process in the near future. Therefore, the development of an environmentally conscious technology for the recovery of RE metals is desirable.

From the stand point of environmental harmonization, the electrodeposition using ionic liquids (ILs) is attractive as the effective recovery method of $\mathrm{Nd}$ and Dy metals. ILs have many original properties, such as nonvolatility, noncombustible, and a wide electrochemical window [11, 12]. In particular, the ILs consisting of bis(trifluoromethyl-sulfonyl)amide anion, [TFSA'], are easily dehydrated compared with other ILs that are miscible with water. There are some reports about the electrochemical behavior and electrodeposition of RE elements such as La, $\mathrm{Sm}, \mathrm{Eu}$, and $\mathrm{Yb}$ [13-17] in ILs. We have already demonstrated that the recovery process of $\mathrm{Nd}$ [18-21] and Dy [22, 23] metals by electrodeposition using quaternary phosphonium and ammonium-based ILs, such as triethyl-pentyl-phosphonium bis(trifluoromethyl-sulfonyl)amide, $\left[\mathrm{P}_{2225}\right][\mathrm{TFSA}]$, and 2-hydroxy ethyl-trimethyl-ammonium bis(trifluoromethylsulfonyl)amide, $\left[\mathrm{N}_{1112 \mathrm{OH}}\right][\mathrm{TFSA}]$. In addition to the electrodeposition process using ILs, the wet separation process has been recently indispensable for the recycling of spent $\mathrm{Nd}$-Fe-B magnets. In particular, solvent extraction and precipitation separation are effective wet separation processes. Therefore, we have recently proposed the combination process constituting a wet separation, such as solvent extraction [24, 25] or precipitation separation [26, 27], with electrodeposition [18-23].

In this study, we investigated the nucleation behavior for the initial electrodeposition for $\mathrm{Nd}$ and Dy metals in TFSA-based ILs. In addition, the nucleation and the growth mechanisms of $\mathrm{Nd}$ and Dy nuclei were analyzed by chronoamperometry (CA). Furthermore, the potentiostatic electrodeposition of Nd and Dy metals from TFSA-based ILs was performed, and the obtained electrodeposits were characterized via scanning electron microscopy (SEM), energydispersive X-ray microanalysis (EDX), and X-ray photoelectron spectroscopy (XPS).

\section{Experimental}

\subsection{Preparation}

$\mathrm{Nd}(\mathrm{TFSA})_{3}$ and Dy(TFSA $)_{3}$ were prepared from the reaction for $\mathrm{Nd}_{2} \mathrm{O}_{3}$ (Wako Pure Chemical Industries, Ltd., $>99.9 \%$ ) or $\mathrm{Dy}_{2} \mathrm{O}_{3}$ (Wako Pure Chemical Industries, Ltd., >99.9\%) with 1, 1, 1trifluoro- $\mathrm{N}$-[(trifluoromethyl)sulfonyl]methanesulfone-amide (H[TFSA], Kanto Chemical Co., 
Inc., $>99.0 \%$ ) at $373 \mathrm{~K}$ under agitation. The suspension was clearly transformed to a pale purple (Nd) or a light-yellow (Dy) solution after the reaction between the metallic $\mathrm{Nd}$ and Dy components and the amide acid. Each solution was evaporated at $423 \mathrm{~K}$ in order to remove the unreacted acid components. $\mathrm{Nd}(\mathrm{TFSA})_{3}$ and $\mathrm{Dy}(\mathrm{TFSA})_{3}$ were obtained as a purplish and a yellowish fine powders and dried at $373 \mathrm{~K}$ in a vacuum chamber $(<-0.1 \mathrm{MPa})$ for more than $48 \mathrm{~h}$; the average yield of the synthesized $\mathrm{Nd}(\mathrm{TFSA})_{3}$ and Dy(TFSA $)_{3}$ was confirmed to be $>92.0 \%$.

The phosphonium type of IL, $\left[\mathrm{P}_{2225}\right][\mathrm{TFSA}]$, was synthesized based on the previous procedure described by Tsunashima [28]. The metathesis reaction between $\left[\mathrm{P}_{2225}\right] \mathrm{Br}$ (Nippon Chemical Industrial Co., Ltd., >99.5\%) and Li[TFSA] (Kanto Chemical Co., Inc., 99.7\%) proceeded to obtain $\left[\mathrm{P}_{2225}\right][\mathrm{TFSA}]$. The crude IL was purified by cleaning several times with distilled water. All bromide anions were perfectly removed from the purified IL, as confirmed by $\mathrm{AgNO}_{3}$ titration. $\left[\mathrm{P}_{2225}\right][\mathrm{TFSA}]$ prepared from this synthesis was dried under high vacuum $(<-0.1 \mathrm{MPa})$ for $72 \mathrm{~h}$ at $393 \mathrm{~K}$. The average yield of IL based on the synthesis was $96.9 \%$. A solution of $\mathrm{Nd}(\mathrm{TFSA})_{3}$ and $\mathrm{Dy}(\mathrm{TFSA})_{3}$ in $\left[\mathrm{P}_{2225}\right][$ TFSA] was used as the electrolyte for the ensuing experiment and was prepared by adding an appropriate amount of $\mathrm{Nd}(\mathrm{TFSA})_{3}$ or $\mathrm{Dy}(\mathrm{TFSA})_{3}$ to $\left[\mathrm{P}_{2225}\right][$ TFSA] inside a glove box (MIWA MFG Co., Ltd., DBO-2LKP-YUM02) filled with $\mathrm{Ar}$ (water and oxygen contents $<1.0 \mathrm{ppm}$ ). These solutions were dried at $373 \mathrm{~K}$ in a vacuum chamber (<-0.1 MPa) for more than $72 \mathrm{~h}$.

\subsection{Electrochemical analysis}

CA was carried out using a three-electrode cell with an electrochemical analyzer (BAS Inc., ALS760D) inside a glove box. The Pt disk electrode (BAS Inc., $\phi=1.6 \mathrm{~mm}$ ) was selected as a working electrode that was mirror polished using alumina and diamond pastes. $\mathrm{Pt}$ wire (BAS Inc., $\phi=0.5 \mathrm{~mm}$ ) was used as a counter electrode for CA. Ag wire immersed in $0.1 \mathrm{~mol} \mathrm{dm}^{-3}$ $\mathrm{Ag}\left[\mathrm{CF}_{3} \mathrm{SO}_{3}\right]$ (Wako Pure Chemical Industries, Ltd., $>97.0 \%$ ) in $\left[\mathrm{P}_{2225}\right]$ [TFSA] was applied as a reference electrode. The potential was compensated for the IL standard using a ferrocene $(\mathrm{Fc}) /$ ferrocenium $\left(\mathrm{Fc}^{+}\right)$redox couple.

The electrodeposition of $\mathrm{Nd}$ and Dy metals from $0.1 \mathrm{~mol} \mathrm{dm}^{-3} \mathrm{Nd}(\mathrm{TFSA})_{3}$ and Dy(TFSA $)_{3}$ in $\left[\mathrm{P}_{2225}\right][$ TFSA] was carried out using a three-electrode system inside a cylindrical cell at $393 \mathrm{~K}$ under an Ar atmosphere $\left(\mathrm{H}_{2} \mathrm{O}, \mathrm{O}_{2}<1.0 \mathrm{ppm}\right)$ in a glove box. A copper substrate and a prismatic $\mathrm{Nd}-\mathrm{Fe}-\mathrm{B}$ rod were employed as a cathode and an anode, respectively. A Vycor glass filter was covered with a soda lime tube at the bottom of anode in order to prevent the diffusion of dissolution components from the anode into the electrolyte. The electrode surface was polished by the suitable fine-grade abrasive papers before experiments. The Pt wire $(\phi=0.5 \mathrm{~mm})$ was used as a quasi-reference electrode (QRE). Moreover, the overpotential under the potentiostatic electrodeposition was $-3.40 \mathrm{~V}$ or $-3.80 \mathrm{~V}$ for the electrodeposition of $\mathrm{Nd}$ or Dy metal, respectively. The surface morphology of the electrodeposits was observed using SEM (JSM-6510LA, JEOL Ltd.), and the chemical composition of electrodeposits was analyzed using EDX (JED-2300, JEOL Ltd.). The metallic states of $\mathrm{Nd}$ and Dy element in the electrodeposits were evaluated using XPS (Quantera SXM, ULVAC-PHI, Inc.). Furthermore, the crystalline state of the metallic Nd and Dy was investigated by XRD (RINT-2500, Rigaku Co.). 


\section{Results and discussions}

\subsection{Nucleation behaviors of $\mathrm{Nd}$ and Dy nuclei}

According to the chronoamperometric analysis, the initial nucleation and the subsequent growth behaviors of $\mathrm{Nd}$ and Dy nuclei were investigated in [ $\left.\mathrm{P}_{2225}\right][\mathrm{TFSA}]$. A distinctive peak was observed on the nucleation process after the current extinction corresponding to the double layer charging. This peak was characteristic of the three-dimensional growth of the $\mathrm{Nd}$ and Dy nuclei; there was an increase tendency of faradaic current based on the nucleation and the subsequent growth of $\mathrm{Nd}$ and Dy nuclei. Eventually, a maximum current density, $j_{\mathrm{m}}$, was reached at a maximum time $t_{\mathrm{m}}$; finally, the current immediately decreased to a limiting diffusion current. As for $\mathrm{Nd}$ nucleation, chronoamperogram was represented with different overpotentials, as shown in Fig. 1.

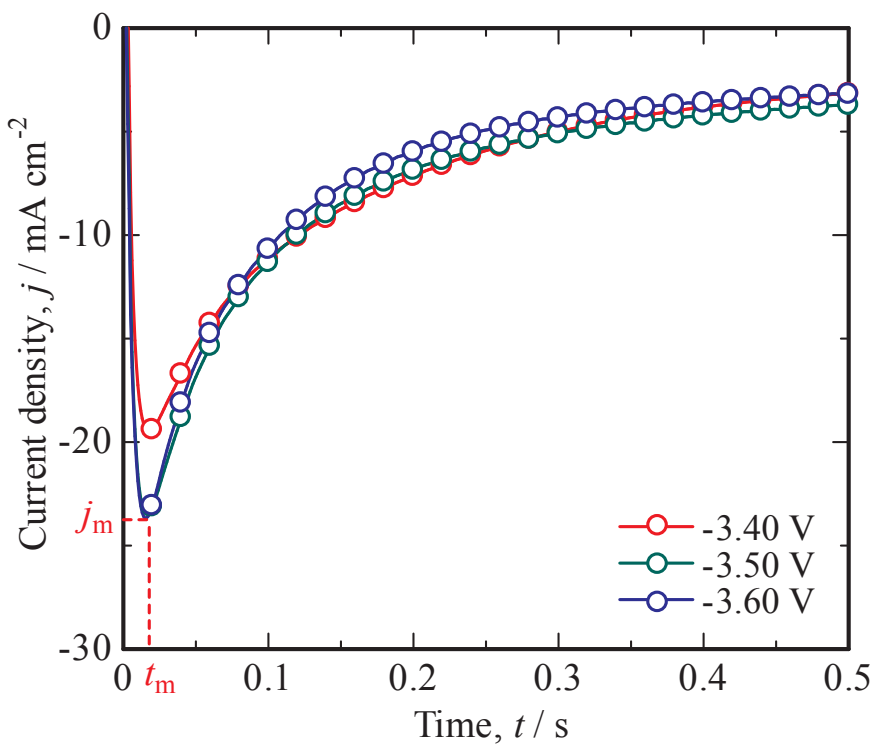

Figure 1. Chronoamperogram on a Pt electrode for $0.1 \mathrm{~mol} \mathrm{dm}^{-3}\left[\mathrm{Nd}^{(\mathrm{III})}(\mathrm{TFSA})_{5}\right]^{2-}$ in $\left[\mathrm{P}_{2225}\right][\mathrm{TFSA}]$ at $353 \mathrm{~K}$.

For the chronoamperogram, the charging current of neat $\left[\mathrm{P}_{2225}\right][\mathrm{TFSA}]$ was deduced from the raw data for $\left[\mathrm{P}_{2225}\right]\left[\right.$ TFSA] containing $0.1 \mathrm{~mol} \mathrm{dm}^{-3}\left[\mathrm{Nd}^{(\mathrm{III})}(\mathrm{TFSA})_{5}\right]^{2-}$ in order to analyze the faradaic current only in the reduction reaction of $\left[\mathrm{Nd}^{(\mathrm{III})}(\mathrm{TFSA})_{5}\right]^{2-}$. Several models have been developed to describe the $j$ - $t$ curves for metal deposition. It has been previously reported that the theoretical methodology developed by Scharifker and Hills [29] is applicable to deposition of several metals from TFSA-based ILs [30-34]. Therefore, the initial stage of nucleation and the crystal growth of $\mathrm{Nd}$ and Dy nuclei were evaluated based on the Hills-Scharifker theory in this investigation. The previous theory related with the three-dimensional nucleation can 


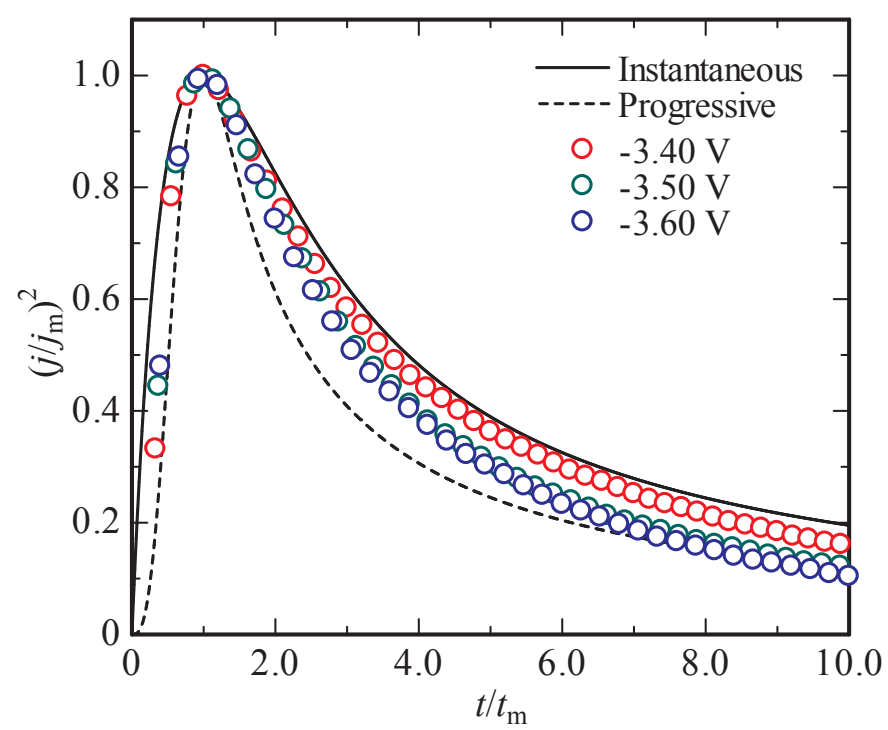

Figure 2. $\left(j / j_{\mathrm{m}}\right)^{2}-t / t_{\mathrm{m}}$ plots for $0.1 \mathrm{~mol} \mathrm{dm}^{-3}\left[\mathrm{Nd}^{(\mathrm{IIII})}(\mathrm{TFSA})_{5}\right]^{2-}$ in $\left[\mathrm{P}_{2225}\right][\mathrm{TFSA}]$ evaluated from CA.

be classified into instantaneous and progressive process. As for the instantaneous nucleation, the nuclei are electrodeposited on the electrode active surface, and the nucleation growth proceeds at a constant rate that is dependent on the induced overpotential. The resultant $j-t$ curves are mathematically described by the following equation:

$$
\left(\frac{j}{j_{m}}\right)^{2}=\frac{1.2254}{t / t_{m}}\left\{1-\exp \left[-2.3367\left(\frac{t}{t_{m}}\right)^{2}\right]\right\}^{2}
$$

where $j$ is the current density at time $t$ and $j_{\mathrm{m}}$ is the maximum current density at time $t_{\mathrm{m}}$. In the case of progressive nucleation, the initially deposited nuclei grow at varying rates dependent on the time of deposition. The $j-t$ curves can be mathematically described by the following equation:

$$
\left(\frac{j}{j_{m}}\right)^{2}=\frac{1.9542}{t / t_{m}}\left\{1-\exp \left[-1.2564\left(\frac{t}{t_{m}}\right)\right]\right\}^{2}
$$

The relationship between the squared dimensionless current density and the dimensionless time of $\left[\mathrm{Nd}^{(\mathrm{III})}(\mathrm{TFSA})_{5}\right]^{2-}$ in $\left[\mathrm{P}_{2225}\right][\mathrm{TFSA}]$ is shown in Fig. 2 . In the case of the overpotential at $-3.40 \mathrm{~V}$, the current tendency was consistent with the instantaneous nucleation process. 
Conversely, when the overpotentials were induced at -3.50 and $-3.60 \mathrm{~V}$, the current curves shifted from that of the instantaneous nucleation process to the progressive nucleation process. A series of experimental results demonstrated that the nucleation process influenced on the induced overpotentials. Thus, the nucleation and the growth process would be correlated with the number density of the active sites from the current transients [35] as discussed below. This transition from instantaneous to progressive nucleation was consistent with the nucleation process for Dy nuclei in our investigations [22]. In the case of Dy nuclei in [ $\left.\mathrm{P}_{2225}\right][\mathrm{TFSA}]$ system, when the overpotential of $-3.60 \mathrm{~V}$ was induced, the nucleation behavior obeyed the instantaneous nucleation process. On the other hand, the nucleation curve at $-3.80 \mathrm{~V}$ was followed by the progressive nucleation process.

The number density was analyzed based on the following procedure: the nucleation number density, $N_{0}$, can be estimated from the maximum current, $j_{\max }$ and the maximum time, $t_{\max }$ of the $j-t$ curve based on the following equation [35]:

$$
N_{0}=0.065\left(8 \pi C_{\mathrm{O}}^{*} M / \rho\right)^{-1 / 2}\left(n F C_{\mathrm{O}}^{*} / j_{\max } t_{\max }\right)^{2}
$$

where $M$ and $\rho$ are the atomic mass and the density of the deposited metal, respectively. During the initial stages of electrodeposition, well before the maxima in the $j$ - $t$ curves, the initial nucleation can be regarded as an effectively instantaneous, i.e., all related nuclei would be considered to have been formed simultaneously [36]. Then, Eq. (3) can be applied to evaluate the value of $N_{0}$ for all systems from the early stage of the current transient. The number of $\mathrm{Nd}$ and Dy nuclei formed in the early stages of nucleation was estimated using this method as listed in Table 1. In general, the nucleation number density would be tended to increase with elevating overpotential on progressive nucleation process, e.g., the Sn nucleation [37] in 1ethyl-3-methylimidazolium chloride, tetrafluoro-borate, $\left[\mathrm{C}_{2} \mathrm{C}_{1} \mathrm{Im}\right]\left[\mathrm{Cl}, \mathrm{BF}_{4}\right]$. Contrary to our expectations, the number density of $\mathrm{Nd}$ and $\mathrm{Dy}$ nuclei tended to decrease as the overpotential gradually induced in this study. This phenomenon would be correlated with the transition from instantaneous to progressive process. It was also reported that the rate of nucleation was influenced from the overpotential for instantaneous or progressive process [38]. Thus, the different nucleation rate on instantaneous or progressive process would be related with the nucleation number density. The mechanism of $\mathrm{Nd}$ and Dy [22] nucleation revealed that the number density of nuclei is dependent on the overpotential, suggesting that the applied overpotential for electrodeposition becomes important factor from the perspective of the nucleation mechanism as well as the number of nuclei.

\begin{tabular}{lccc}
\hline Applied potential $(E)$ for $N d$ nucleation $/ \mathrm{V}$ & -3.40 & -3.50 & -3.60 \\
\hline Nucleation number density $\left(10^{11} N_{0}\right) / \mathrm{cm}^{-2}$ & 2.0 & 1.7 & 1.7 \\
\hline Applied potential $(E)$ for Dy nucleation $/ \mathrm{V}$ & -3.40 & -3.60 & -3.80 \\
\hline Nucleation number density $\left(10^{11} N_{0}\right) / \mathrm{cm}^{-2}$ & 6.3 & 5.5 & 2.6 \\
\hline
\end{tabular}

Table 1. The nucleation number density of $\mathrm{Nd}$ and Dy nuclei from $j-t$ curves at each applied potential. 


\subsection{Electrodeposition of $\mathrm{Nd}$ and Dy metals}

Electrodeposition at $-3.40 \mathrm{~V}$ produced blackish electrodeposits on a $\mathrm{Cu}$ substrate. The total transported charge was 105.8 C. The SEM image of the electrodeposits was shown in Fig. 3.

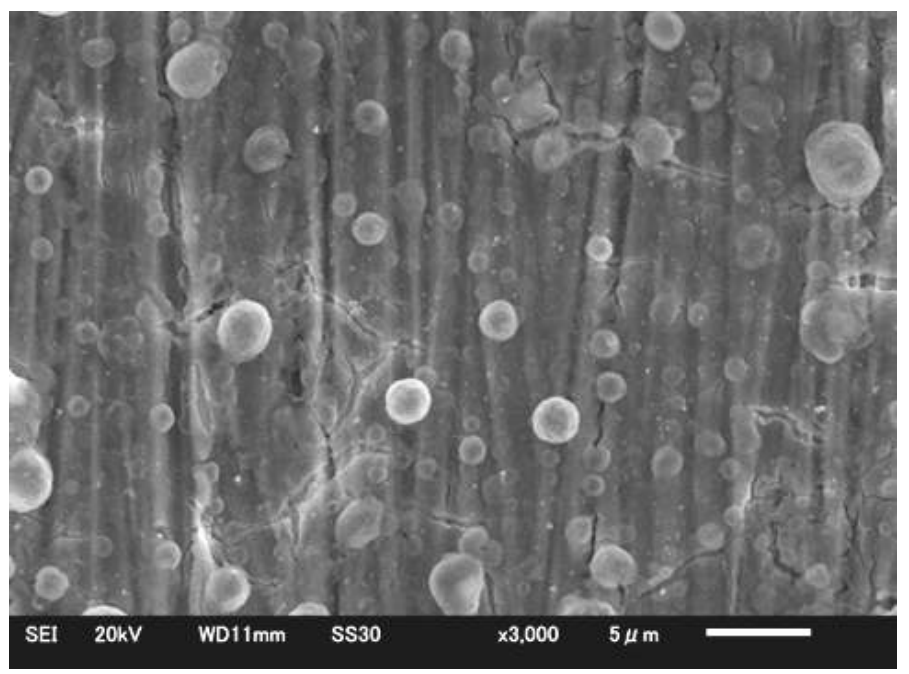

Figure 3. The SEM image of electrodeposits obtained by potentiostatic electrodeposition induced at $-3.40 \mathrm{~V}$.

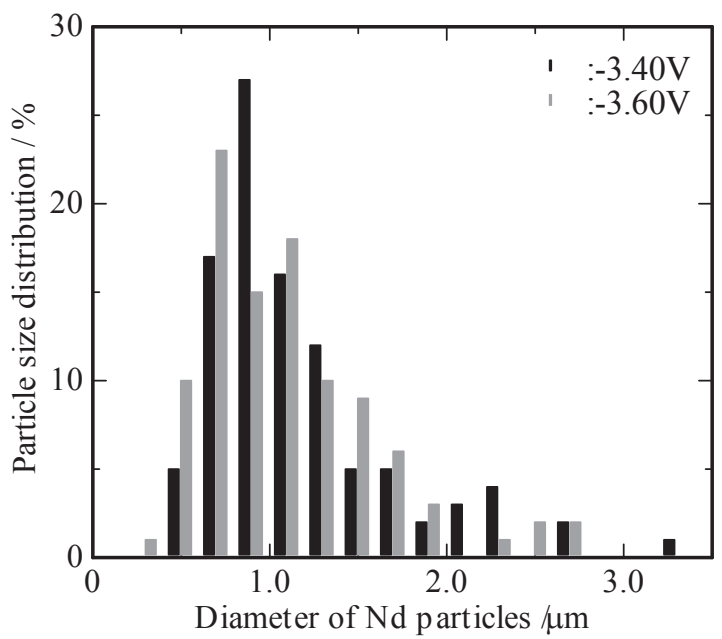

Figure 4. The size distribution of the electrodeposited Nd particles evaluated from each SEM image. 
The surface morphology of the electrodeposits was heterogeneous orbicular with a nonuniform size distribution. This behavior would be generated from the initial nucleation and the subsequent growth occurred according to the progressive nucleation process in which the rate of the nucleation was faster than that of the crystal growth. From above-mentioned nucleation behaviors, at $-3.40 \mathrm{~V}$, the $j-t$ curve would be fitted to the theoretical line for instantaneous nucleation process, but the line gradually shifted to the progressive nucleation process. As a result, the electrodeposition result was consistent with the data for the initial nucleation and growth of Nd nuclei in $\left[\mathrm{P}_{2225}\right][\mathrm{TFSA}]$ by CA discussed above. With the use of applied overpotentials of $-3.40 \mathrm{~V}$, the average diameter of the $\mathrm{Nd}$ particles was $1.17 \mu \mathrm{m}$, as shown in Fig.4. The particle size of the electrodeposits obtained by electrodeposition at $-3.60 \mathrm{~V}$ was smaller than that achieved at $-3.40 \mathrm{~V}$. The number of particles electrodeposited at $-3.60 \mathrm{~V}$ was also larger than that at $-3.40 \mathrm{~V}$. A series of results were also consistent with the CA results, which represented that the number density of $\mathrm{Nd}$ nuclei tended to increase with elevating the overpotential. The quantitative analysis for the electrodeposits at -3.40 and $-3.60 \mathrm{~V}$ evaluated from EDX was listed in Table 2.

\begin{tabular}{cccccccc}
\hline Overpotential/V & $\mathbf{C}$ & $\mathbf{N}$ & $\mathbf{O}$ & $\mathbf{F}$ & $\mathrm{S}$ & $\mathrm{Fe}$ & $\mathbf{N d}$ \\
\hline-3.40 & 1.26 & 0.94 & 20.36 & 2.83 & 0.89 & 0.23 & 73.49 \\
\hline-3.60 & 1.15 & 0.78 & 23.69 & 3.26 & 1.21 & 0.38 & 69.53 \\
\hline
\end{tabular}

Table 2. The composition (wt.\%) of the electrodeposits obtained by potentiostatic electrodeposition induced at -3.40 and $-3.60 \mathrm{~V}$ from $0.1 \mathrm{~mol} \mathrm{dm}^{-3}\left[\mathrm{Nd}^{\text {(III) }}(\mathrm{TFSA})_{5}\right]^{2}$ in $\left[\mathrm{P}_{2225}\right][\mathrm{TFSA}]$ at $353 \mathrm{~K}$.

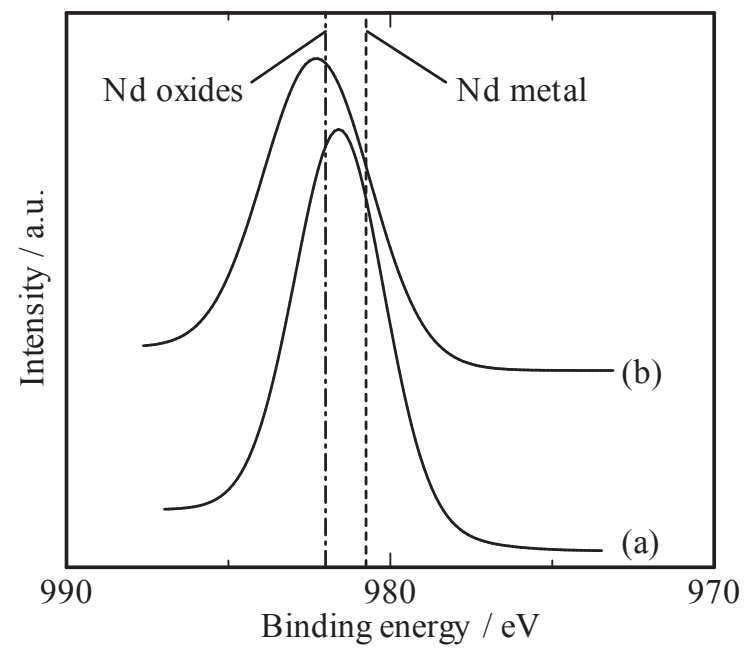

Figure 5. The $\mathrm{Nd} 3 \mathrm{~d}_{5 / 2}$ spectra of the electrodeposits obtained by XPS analysis. (a) The spectrum for middle layer under $0.75 \mu \mathrm{m}$ of the electrodeposits. (b) The spectrum for the top surface of the electrodeposits. 
The EDX data display electrodeposits at -3.40 and $-3.60 \mathrm{~V}$, which mainly consist of Nd metal. However, a relatively large amount of oxygen was also detected at the top surface in the electrodeposits, indicating that a part of $\mathrm{Nd}$ metal would be oxidized due to the active metal. Thus, the oxidizing state of Nd metal in the electrodeposits was evaluated from XPS with Ar etching. Fe element was scarcely detected in the electrodeposits at both overpotentials. As a result, the separated anode structure from the main electrolyte by the Vycor glass filter was confirmed to be an effective strategy. The decomposition of the ILs was prevented by this separated anode structure. Thus, this separated anode structure and the dissolution of anode compartment enabled the acquisition of $\mathrm{Nd}$ metal in the electrodeposits while preventing bonding with the light elements. The $\mathrm{Nd} 3 \mathrm{~d}_{5 / 2}$ XPS spectra of the electrodeposits at -3.40 and $-3.60 \mathrm{~V}$ were shown in Figs. 5(a) and 5(b), respectively. The electrodeposited surfaces were sputtered by an Arion beam to facilitate in-depth analysis of the middle layer, that is, (a) under $0.75 \mu \mathrm{m}$ and (b) the top surface of the electrodeposits. The binding energy of $\mathrm{Nd} 3 \mathrm{~d}_{5 / 2}$ for $\mathrm{Nd}$ metal and oxides should be theoretically positioned at 980.5-981.0 and 981.7-982.3 eV, respectively [39]. The $\mathrm{Nd} 3 \mathrm{~d}_{5 / 2}$ peak maxima acquired for the middle layers (a) under $0.75 \mu \mathrm{m}$ and (b) the top surface were detected at 981.57 and $982.25 \mathrm{eV}$, respectively. Hence, the electrodeposits were identified as $\mathrm{Nd}$ metal and oxide mixtures. It is conjectured that metallic $\mathrm{Nd}$ should initially be electrodeposited on a $\mathrm{Cu}$ substrate and subsequently oxidized by the oxygen in ILs. It has reported that the water content of the ILs did not significantly affect the oxidation sate of the electrodeposits but would influence the coordination number of the $\mathrm{Nd}$ complex [18]. Therefore, the sufficient dehydration and control of the water content of the ILs, including metallic components, are important factors for achieving the recovery of metallic $\mathrm{Nd}$ with high purity.

As for the electrodeposition of Dy metal, the potentiostatic electrodeposition at $-3.80 \mathrm{~V}$ in $\left[\mathrm{P}_{2225}\right][$ TFSA $]$, including $0.1 \mathrm{~mol} \mathrm{dm}^{-3}\left[\mathrm{Dy}^{(\mathrm{III})}(\mathrm{TFSA})_{5}\right]^{2-}$, was performed at $393 \mathrm{~K}$, according to the above-mentioned nucleation analyses. The potentiostatic electrolysis was conducted in a glove box with stirring at $500 \mathrm{rpm}$ to increase the current density by intermittently supplying the electroactive species [Dy (III) $\left.(\mathrm{TFSA})_{5}\right]^{2-}$ to the reactive electrode surface. The total transported charge under Dy electrodeposition was $300 \mathrm{C}$ for $43.6 \mathrm{~h}$. There was no decomposition reaction of IL under Dy electrodeposition since there was no alternation on the light-yellow electrolyte before and after electrodeposition. The blackish-brown electrodeposits with a strong adhesion were observed on a $\mathrm{Cu}$ cathode substrate. A microanalytical SEM/EDX method was applied to the analysis of the surface morphology and the element content of the electrodeposits. The EDX results with SEM image are shown in Figs. 6(a) and 6(b), respectively.

From Fig. 6(b), the round particles on a Cu substrate were confirmed to be Dy metal and other related compounds. A quantitative analysis of the electrodeposits is tabulated in Table 3.

Most parts of the electrodeposits were composed of the Dy metallic state because almost no oxygen was detected on the Dy metals from the EDX analysis. The amounts of carbon and oxygen were derived from the surface of the $\mathrm{Cu}$ cathode substrate. The Dy metals with ca. 0.8-0.9 $\mu \mathrm{m}$ particles were highly distributed in the electrodeposits. This electrodeposition 
(a)

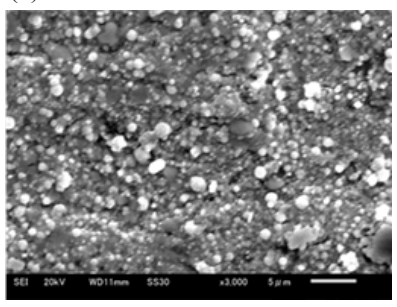

(b)
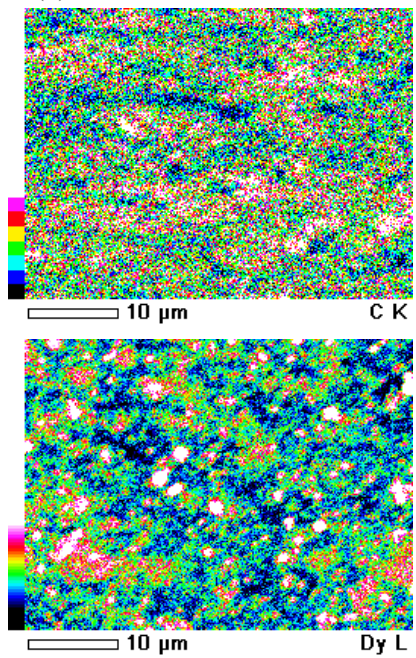
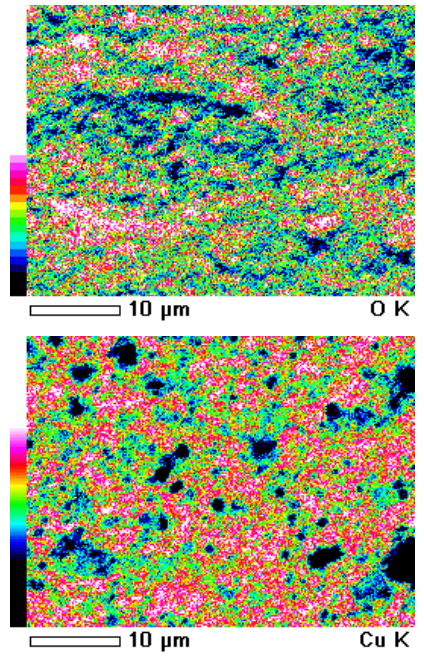

Figure 6. (a) The SEM image and (b) EDX analysis of Dy electrodeposits on a Cu substrate under potentiostatic electro-

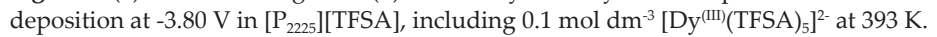

\begin{tabular}{ccccccccc}
\hline Overpotential/V & $\mathbf{C}$ & $\mathbf{N}$ & $\mathbf{O}$ & $\mathbf{F}$ & $\mathbf{P}$ & $\mathbf{S}$ & $\mathbf{D y}$ & $\mathbf{C u}$ \\
\hline-3.80 & 10.83 & 1.15 & 11.82 & 3.87 & 0.86 & 1.87 & 9.27 & 60.33 \\
\hline
\end{tabular}

Table 3. The composition (wt.\%) of the electrodeposits on a $\mathrm{Cu}$ substrate obtained by potentiostatic electrodeposition

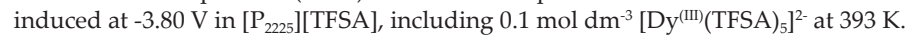

enabled us to conclude that Dy electrodeposits contained a smaller amount of the oxide state and a large amount of the metallic state on the electrode top surface. We also investigated the depth components of the electrodeposits by XPS with the Al-K $\alpha$ radiation. The Dy $3 \mathrm{~d}_{5 / 2}$ spectra for the top surface and the middle layer at the depth of $0.5 \mu \mathrm{m}$ of the Dy electrodeposits are represented in Figs. 7(a) and 7(b), respectively. The XPS analysis with Ar sputtering at the rate of $27.2 \mathrm{~nm} \mathrm{~min}{ }^{-1}$ was performed on the Dy electrodeposits. The Dy $3 \mathrm{~d}_{5 / 2}$ spectra for Dy metal and oxides were theoretically positioned at 1295.8 and $1289.0 \mathrm{eV}$, respectively [30]. The Dy $3 \mathrm{~d}_{5 / 2}$ peaks of the electrodeposits were assigned at $1297.2 \mathrm{eV}$ and were hardly shifted by Ar etching treatment. The Dy $3 \mathrm{~d}_{5 / 2}$ spectra of the middle layer and the top surface showed a good agreement with the theoretical value. The XRD result of the Dy electrodeposits is shown in Fig. 8. The Dy metallic crystal planes at a low angle were in good accordance with the ASTM card. Consequently, a series of electrodeposition investigations of $\mathrm{Nd}$ and Dy electrodeposits allowed us to conclude that most of the metallic state of $\mathrm{Nd}$ and $\mathrm{Dy}$ can be recovered from a TFSA-based IL by the potentiostatic electrodeposition with elevating temperatures. 


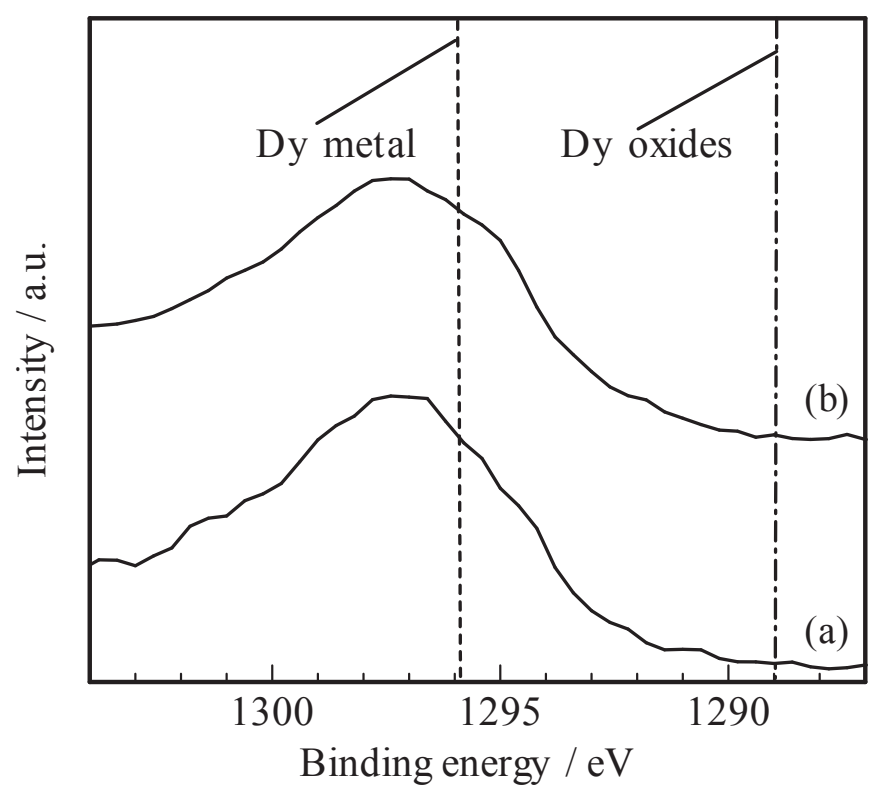

Figure 7. The Dy $3 d_{5 / 2}$ spectra of the Dy electrodeposits by XPS analysis. (a) The top surface of the electrodeposits. (b) The middle layer under $0.5 \mu \mathrm{m}$ of the electrodeposits.

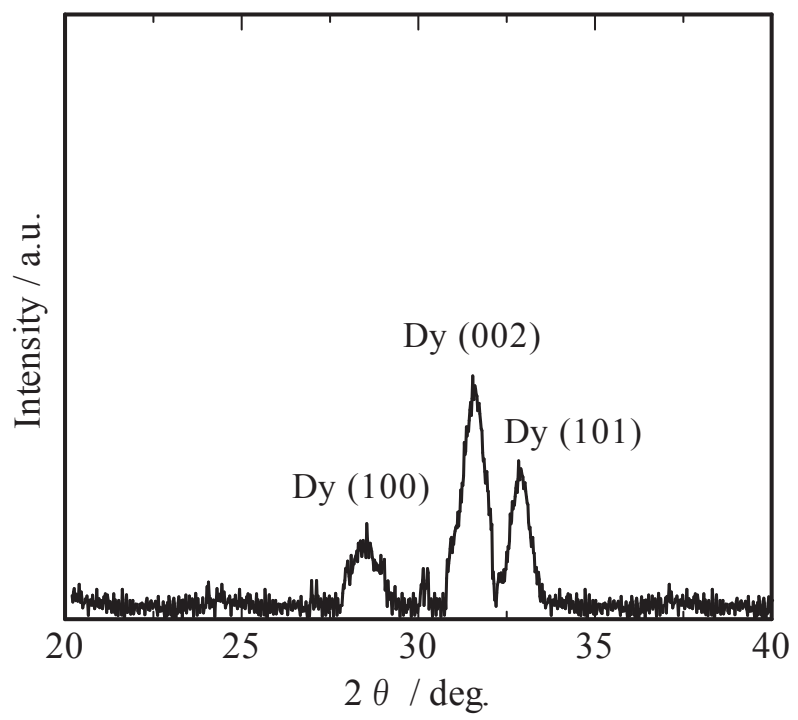

Figure 8. XRD profile of the Dy electrodeposits on a Cu substrate under potentiostatic electrodeposition at $-3.80 \mathrm{~V}$. 


\section{Acknowledgements}

This study was partially supported by the Grant-in-Aid for Scientific Research (No. 15H02848) from the Ministry of Education, Culture, Sports, Science and Technology, Japan.

\section{Author details}

Masahiko Matsumiya

Address all correspondence to: mmatsumi@ynu.ac.jp

Graduate School of Environment and Information Sciences, Yokohama National University, Tokiwadai, Hodogaya-ku, Yokohama, Japan

\section{References}

[1] D. Yuan, Y. Liu, Mater. Chem. Phys., 96 (2006) 79-83.

[2] H. Yoshida, S. Kato, K. Hirano, J. Nishimoto, T. Hattori, Chem. Lett., 36(3) (2007) 430-431.

[3] A.A. Dakhel, Mater. Chem. Phys., 102 (2007) 266-270.

[4] N. Oono, M. Sagawa, R. Kasada, H. Matsui, A. Kimura, J. Magn. Magn. Mater., 323 (2011) 297-300.

[5] Y. Matsuura, J. Magn. Magn. Mater., 303 (2006) 344-347.

[6] O. Takeda, T. Okabe, Y. Umetsu, J. Alloys Compd., 408-412 (2006) 387-390.

[7] G. Yan, P.J. McGuiness, J.P.G. Farr, I.R. Harris, J. Alloys Compd., 478 (2009) 188-192.

[8] S. Kobayashi, K. Kobayashi, T. Nohira, R. Hagiwara, T. Oishi, H. Konishi, J. Electrochem. Soc., 158 (2011) E142-E146.

[9] T. Uda, Mater. Trans., 43(1) (2002) 55-62.

[10] O. Takeda, T.H. Okabe, Y. Umetsu, J. Alloys Compd., 408-412 (2006) 387-390.

[11] D.R. MacFarlane, M. Forsyth, P.C. Howlett, J.M. Pringle, J. Sun, G. Annat, W. Neil, E.I. Izgorodina, Acc. Chem. Res., 40 (2007) 1165-1173.

[12] W. Simka, D. Puszczyk, G. Nawrat, Electrochim. Acta, 54 (2009) 5307-5319.

[13] S. Legeai, S. Diliberto, N. Stein, C. Boulanger, J. Estager, N. Papaiconomou, M. Draye, Electrochem. Commun., 10 (2008) 1661-1664. 
[14] M. Yamagata, Y. Katayama, Y. Miura, J. Electrochem. Soc., 153 (2006) E5-E9.

[15] A. I. Bhatt, I. May, V. A. Volkovich, D. Collison, M. Helliwell, I. B. Polovov, R. G. Lewin, Inorg. Chem., 44(14) (2005) 4934-4940.

[16] K. Binne, Chem. Rev., 107 (2007) 2592-2614.

[17] Y. Katayama, Electrochemical Aspects of Ionic Liquids, (2005) 111-131.

[18] H. Kondo, M. Matsumiya, K. Tsunashima, S. Kodama, Electrochim. Acta, 66 (2012) 313-319.

[19] H. Kondo, M. Matsumiya, K. Tsunashima, S. Kodama, ECS Trans., 50(11) (2012) 529-538.

[20] M. Ishii, M. Matsumiya, S. Kawakami, ECS Trans., 50(11) (2012) 549-560.

[21] M. Matsumiya, M. Ishii, R. Kazama, S. Kawakami, Electrochim. Acta, 146 (2014) 371-377.

[22] R. Kazama, M. Matsumiya, N. Tsuda, K. Tsunashima, Electrochim. Acta, 113 (2013) 269-279.

[23] A. Kurachi, M. Matsumiya, K. Tsunashima, S. Kodama, J. Appl. Electrochem., 42 (2012) 961-968.

[24] M. Matsumiya, Y. Kikuchi, T. Yamada, S. Kawakami, Sep. Purif. Technol., 130 (2014) 91-101.

[25] Y. Kikuchi, M. Matsumiya, S. Kawakami, Solv. Extr. Res. Dev., 21(2) (2014) 137-145.

[26] K. Ishioka, M. Matsumiya, M. Ishii, S. Kawakami, Hydrometallurgy, 144-145 (2014) 186-194.

[27] M. Matsumiya, K. Ishioka, T. Yamada, M. Ishii, S. Kawakami, Inter. J. Miner. Process., 126 (2014) 62-69.

[28] K. Tsunashima, M. Sugiya, Electrochem. Commun., 9 (2007) 2353-2358.

[29] B. Scharifker, G. Hills, Electrochim. Acta, 28 (1983) 879-889.

[30] Y. Bando, Y. Katayama, T. Miura, Electrochim. Acta, 53 (2007) 87-91.

[31] N. Tachikawa, N. Serizawa, Y. Katayama, T. Miura, Electrochim. Acta, 53 (2008) 6530-6534.

[32] Y.-L. Zhu, Y. Kozuma, Y. Katayama, T. Miura, Electrochim. Acta, 54 (2009) 7502-7506.

[33] A. Basile, A.I. Bhatt, A.P. O'Mullane, S.K. Bhargava, Electrochim. Acta, 56 (2011) 2895-2905.

[34] R. Fukui, Y. Katayama, T. Miura, J. Electrochem. Soc., 158(9) (2011) D567-D572.

[35] J. Mostany, J. Mozota, B.R. Scharifker, J. Electroanal. Chem., 177 (1984) 25-37. 
[36] G.A. Gunawardena, G.J. Hills, I. Montenegro, Electrochim. Acta, 23 (1978) 693-697.

[37] M.-H. Yang, I.-W. Sun, J. Appl. Electrochem., 33 (2003) 1077-1084.

[38] D. Grujicic, B. Pesic, Electrochim. Acta, 50 (2005) 4426-4443.

[39] J.F. Moulder, W.F. Stickle, P.E. Sobol, K.D. Bomben, Handbook of X-ray Photoelectron Spectroscopy, Perkin-Elmer Corp., Eden Prairie, MN (1992). 